\title{
Effect of Gilsonite Use on Storage Stability of Styrene-butadiene-styrene Modified Bitumen
}

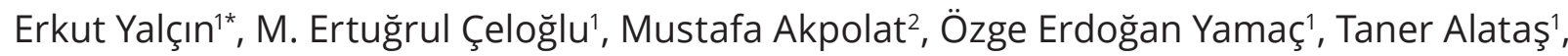 \\ Baha Vural Kök¹, Mehmet Yılmaz \\ 1 Department of Civil Engineering, \\ Faculty of Engineering, \\ Firat University, 23119, Elazı ̆̆, Turkey \\ 2 Department of Civil Engineering, \\ Faculty of Engineering, \\ Munzur University, 62000, Tunceli, Turkey \\ *Corresponding author, e-mail: erkutyalcin@firat.edu.tr
}

Received: 08 July 2018, Accepted: 03 July 2019, Published online: XX Xxxxxxxx 201X

\begin{abstract}
Styrene-butadiene-styrene (SBS) polymer is one of the most preferred additives to improve performance in hot mix asphalt pavements. The storage instability, in other words, the separation of a polymer-rich phase from the bitumen-rich phase in the course of storage and transportation is one of the prevalent problems in SBS modified bitumen. The present study attempted to obtain modified bitumen at the same performance level with the SBS modified bitumen, but stable with respect to the storage stability. For this purpose, both SBS and American Gilsonite (AG) were used in modified bitumen production. It was determined that modified bitumen at the same performance level was obtained with the use of $5 \%$ SBS or $18 \%$ AG in bitumen modification. It was also determined that the performance levels of the modified bitumen obtained with the use of $2 \%$ SBS $+13 \%$ AG, $3 \%$ SBS $+10 \%$ AG and $4 \%$ SBS $+6 \%$ AG were similar. Additionally, $2 \%, 3 \%$ and $4 \%$ SBS modified bitumen were used for the assessment of storage stability properties of the SBS modified binders. These 8 different modified bitumen samples were tested for storage stability based on the EN 13399 standard. Penetration, softening point, rotational viscometer, bending beam rheometer, and dynamic shear rheometer tests were conducted on the samples. Based on all conducted tests, it was determined that more stable binders were obtained with the use of AG and SBS in terms of storage stability compared to solely SBS modified bitumen.
\end{abstract}

Keywords

storage stability, bitumen, modification, styrene-butadiene-styrene, American Gilsonite

\section{Introduction}

Highway flexible pavements primarily experience deteriorations such as rutting, low temperature and fatigue cracking, moisture-induced damages and ageing. These deteriorations are mainly due to the rheological and mechanical properties of the bitumen. Additives are used to delay these deteriorations and extend the service life of the pavements. The additives can be added to bituminous binders, but they can also be introduced directly into the mixture in plants [1].

Various materials such as polymers, natural asphalts (Gilsonite), and sulfur have been used in bitumen modification; these additives improved the rheological properties of bitumen and the mechanical properties of hot mix asphalts [2-6]. In order to manage the natural resources more efficiently, waste materials are recycled and some of them such as waste polymers are incorporated into asphalt mixes, thus natural resources are preserved and material properties are improved [7-9]. Among the additives used in bitumen, polymer type materials are the most frequently used ones [10]. The polymers are divided into two groups; elastomers and plastomers. SBS, an elastomer, demonstrated greater potential compared to other modifiers when blended with bitumen; it improved the mechanical properties and the rheological behavior of the conventional bitumen [11-15]. Natural asphalts, such as Gilsonite and Trinidad Lake Asphalt, are among the other additives. 
Gilsonite, which is found particularly in America and Iran in abundance, can easily mix with bitumen due to their similar structures [16]. Thus, Gilsonite was used in various studies for bitumen modification and it was reported that bitumen performance increased as a result [17, 18]. Furthermore, it was reported that a considerable cost reduction can be achieved in the end products by partially or completely replacing the widely-used bitumen modifier, SBS polymer with Gilsonite [19].

When SBS is mixed with bitumen, several interactions occur between bitumen and SBS. The interaction between bitumen and polybutadiene blocks (PB) that occurs in intermolecular level is more powerful compared to those that occur with polystyrene blocks [20]. It was suggested that polybutadiene blocks interact with positively charged groups of bitumen through their $\pi$-electrons, however polystyrene blocks exhibit an interaction with electron-rich groups in bitumen via their aromatic protons. Polystyrene blocks in SBS copolymers, when added to bitumen, may absorb certain saturated branches and certain rings in the light component of bitumen [21, 22]. This, in return, leads to the swelling of polystyrene blocks and hardens the bitumen [23]. If the polymer content is low, SBS is dispersed as a discrete phase in the bitumen. When SBS concentration increases, phase inversion process may begin in the modified bitumen. It is ideal that two interlocked continuous phases are formed as bitumen-rich phase and SBS-rich phase. SBS-rich phase includes two sub-phases of swollen polybutadiene matrix and essentially pure polystyrene domains. As soon as the SBSrich phase occurs, a rubbery supporting network is also formed in the modified bitumen. This network increases complex modulus $\left(\mathrm{G}^{*}\right)$ and viscosity, improves elastic response and enhances resistance to cracking at low temperatures in SBS-modified bitumen [24].

Although SBS is a popular modifier of paving bitumen owing to the reported properties, SBS copolymers are not exactly ideal modifiers. For instance, the compatibility between bitumen and SBS is not perfect $[25,26]$. Storage instability is a commonly identified problem in the final polymer modified bitumen (PMB) products. This process entails the separation of polymer-rich phase from bitumen-rich phase, which occurs during storage and transport. Since storage stability is a major requirement for all PMBs, comprehension of the stability-related behavior of PMB has always been an important objective in this research field during the past decades.
In the present study, SBS modified bitumen was investigated in order to acquire binders, which exhibit the same performance but with more stability in storage. Storage stability of binders was analyzed with penetration, softening point, rotational viscometer, bending beam rheometer, and dynamic shear rheometer (DSR) tests. The most adequate additive for storage and its ideal rate were investigated and the effects of the use of SBS and AG in conjunction with storage stability were examined.

\section{Material and method \\ 2.1 Material}

In the study, 160/220 class pure binder, procured from Batman TÜPRAŞ refinery in Turkey, was used as the main binder. SBS (Kraton D 1101), procured from the Shell Company, and Gilsonite, procured from the American Gilsonite Company, were employed as additives. All modified bitumen was obtained by mixing pure bitumen with the additive at $180^{\circ} \mathrm{C}$ and $1000 \mathrm{rpm}$ for 1 hour [27].

The additive that was used in the study was determined based on the findings reported in a previous study [28]. Since the utilized additives and pure binders were similar, the same additive rates were used in the study. Based on the references in the previous study, $5 \% \mathrm{SBS}, 18 \%$ American Gilsonite, $2 \% \mathrm{SBS}+13 \%$ AG, $3 \% \mathrm{SBS}+10 \%$ $\mathrm{AG}$, and $4 \% \mathrm{SBS}+6 \% \mathrm{AG}$ were used based on the weight of bitumen in the rest of the study. Furthermore, in order to reveal the storage stability of SBS more clearly, $2 \%$, $3 \%$ and $4 \%$ SBS modified binders were produced and subjected to the tests. DSR test results for unaged binders are presented in Table 1.

Table 1 DSR Test results for SBS modified unaged binders

\begin{tabular}{|c|c|c|c|c|c|c|c|c|}
\hline \multirow[t]{2}{*}{$\begin{array}{l}\text { SBS } \\
\text { Content } \\
(\%)\end{array}$} & \multirow[t]{2}{*}{$\begin{array}{c}\text { AG } \\
\text { Content } \\
(\%)\end{array}$} & \multicolumn{6}{|c|}{$\begin{array}{c}\mathrm{G}^{*} / \sin \delta(\mathrm{kPa})(\text { Specification limit } \\
\text { min. } 1 \mathrm{kPa}) \\
\text { Temperature }\left({ }^{\circ} \mathrm{C}\right)\end{array}$} & \multirow{2}{*}{ 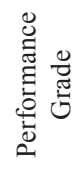 } \\
\hline & & 52 & 58 & 64 & 70 & 76 & 82 & \\
\hline 0 & 18.0 & - & 12.03 & 5.85 & 3.04 & 1.50 & 0.82 & PG 76 \\
\hline 2.0 & 0 & - & 2.73 & 1.26 & 0.65 & - & - & PG 64 \\
\hline 3.0 & 0 & - & 3.42 & 1.64 & 0.84 & - & - & PG 64 \\
\hline 4.0 & 0 & - & 5.99 & 3.11 & 1.62 & - & - & PG 70 \\
\hline 5.0 & 0 & - & 7.77 & 4.31 & 2.37 & 1.37 & 0.85 & PG 76 \\
\hline 2.0 & 13.0 & - & 10.94 & 5.70 & 2.89 & 1.50 & 0.80 & PG 76 \\
\hline 3.0 & 10.0 & - & 10.57 & 5.60 & 2.81 & 1.48 & 0.81 & PG 76 \\
\hline 4.0 & 6.0 & - & 9.48 & 5.10 & 2.62 & 1.41 & 0.76 & PG 76 \\
\hline \multicolumn{2}{|c|}{$\begin{array}{l}\text { Pure Bitumen } \\
\text { (PG 52-28) }\end{array}$} & 2.02 & 0.96 & - & - & - & - & PG 52 \\
\hline
\end{tabular}




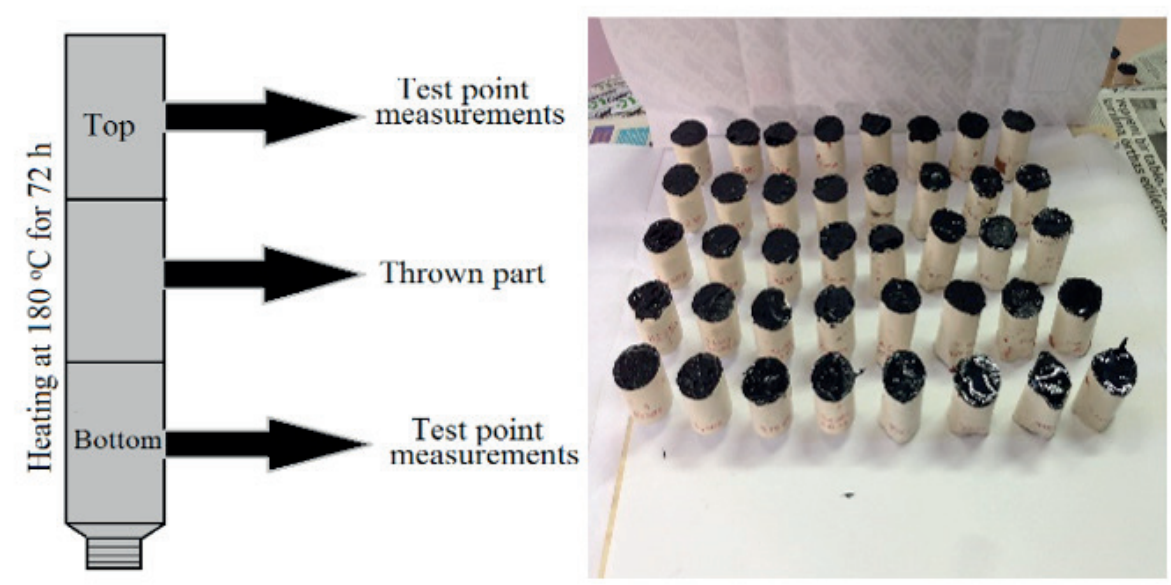

Fig. 1 Test specimens obtained with storage stability test

\subsection{Methods}

\subsubsection{Storage stability test}

The storage stability tests were conducted according to the EN 13399 standards on modified bitumen [29]. In the test, standard aluminum tubes, $160 \mathrm{~mm}$ in height and 30-40 $\mathrm{mm}$ in diameter, were used. Modified bitumen was mixed in a special mixer until it was homogenous according to the standards and poured into the standard tube until it reached a height of 100-120 mm and there were no air bubbles. Then the tube lid was closed airtight. The tubes were stored vertically at $180{ }^{\circ} \mathrm{C}$ for $72 \pm 1$ hours. At the end of this period, the tubes were removed from the stove and were cooled down vertically at room temperature. Subsequently, they were stored at $20{ }^{\circ} \mathrm{C}$ for $30 \mathrm{~min}-$ utes and the bitumen was extracted by removing the lid on the aluminum tubes. The bitumen extracted from the tubes were separated vertically into three equal pieces (Fig. 1). The top and the bottom pieces were subjected to binder tests following the removal of the middle piece. Binder tests were conducted on the acquired samples.

\subsubsection{Conventional binder test}

In the study, binder penetration values were determined based on the EN 1426 standard [30] and binder softening points were determined based on the EN 1427 standard [31]. Thus, consistencies of samples subjected to the stability tests were determined with conventional tests.

\subsubsection{Rotational viscometer test}

Rotational viscometer test was conducted to determine the consistency and pumpability of bituminous binders according to the ASTM D 4402 standard [32]. In the study, rotational viscometer test was conducted under two different temperatures $\left(135^{\circ} \mathrm{C}\right.$ and $\left.165^{\circ} \mathrm{C}\right)$.

\subsubsection{Bending beam rheometer (BBR) test}

The bending beam rheometer (ATS Instrument Company) was used to perform creep tests based on the AASHTO TP1 standard [33]. The experimental temperature was set at $-20{ }^{\circ} \mathrm{C}$. A sample beam (125 $\mathrm{mm}$ in length, $12.5 \mathrm{~mm}$ in width and $6.25 \mathrm{~mm}$ in thickness) was immersed in a bath under constant temperature, and it was stored at the experimental temperature for $60 \mathrm{~min}$. Then, supported on two ends, the binder beam was subjected to a constant load of $100 \mathrm{~g}$, and the deflection on the center point was continuously measured. The binder creep stiffness (S) and creep rate $(\mathrm{m})$ were determined for a load period of $60 \mathrm{~s}$ [34]. Additionally, the physical hardening was determined after a period of $24 \mathrm{~h}$ at $-20{ }^{\circ} \mathrm{C}$ temperature.

\subsubsection{Dynamic mechanical analysis}

Currently, the dynamic mechanical method that utilizes an oscillatory-type test within the linear viscoelastic (LVE) response area is the most frequently employed method for fundamental bitumen rheological tests. Dynamic shear rheometer (DSR) is employed to perform the above-mentioned oscillatory tests.

A Bohlin DSRII rheometer was used to conduct the DSR test on modified binders. With the use of frequency sweeps between 0.001 and $4 \mathrm{~Hz}$ and at a temperature between 40 and $80{ }^{\circ} \mathrm{C}$, the test was carried out under controlled-stress loading conditions. The experiments were conducted with a $25 \mathrm{~mm}$ diameter, $1 \mathrm{~mm}$ gap geometry. For all experiments, the stress amplitude was restricted within the linear viscoelastic response of the bitumen.

The magnitude of the complex shear modulus $\left(\mathrm{G}^{*}\right)$ and phase angle $(\delta)$ are the main viscoelastic parameters acquired with the DSR. The $\mathrm{G}^{*}$ is the rate of maximum (shear) stress to maximum strain. The total resistance 
to deformation, when the bitumen is subjected to shear loading, is measured with the previously mentioned method [35]. Elastic and viscous components specified as (shear) storage modulus $\left(\mathrm{G}^{\prime}\right)$ and (shear) loss modulus $\left(\mathrm{G}^{\prime \prime}\right)$, respectively, are included in this method. The two components mentioned above are associated with the complex (shear) modulus and with each other via the phase (or loss) angle ( $\delta$ ) that represents the phase or time lag between the applied shear stress and shear strain responses in the course of an experiment [22].

\section{Results and discussion}

In the study, 8 different modified bitumen were prepared, and they were subjected to storage stability test according to the EN 13399 standard. Samples acquired with the storage stability test were subjected to penetration, softening point, viscosity, DSR and BBR tests. The test equipment used in the study are presented in Fig. 2. Additionally, the data obtained in the experiments were statistically evaluated through the application of linear regression analysis and the SPSS package software.

\subsection{Penetration test results}

The penetration test results are given in Table 2. In addition, the ratios of penetration test results of the samples obtained from the top and the bottom of the tubes are seen in Fig. 3. The penetration rates of samples obtained from the top of the tubes were higher compared to those acquired from the bottom of the tubes. It was observed that, in modified binders, which only included SBS, as the SBS content increased, the penetration rates of samples obtained from the bottom of the tubes decreased, and thus their consistency increased. It was determined that the penetration

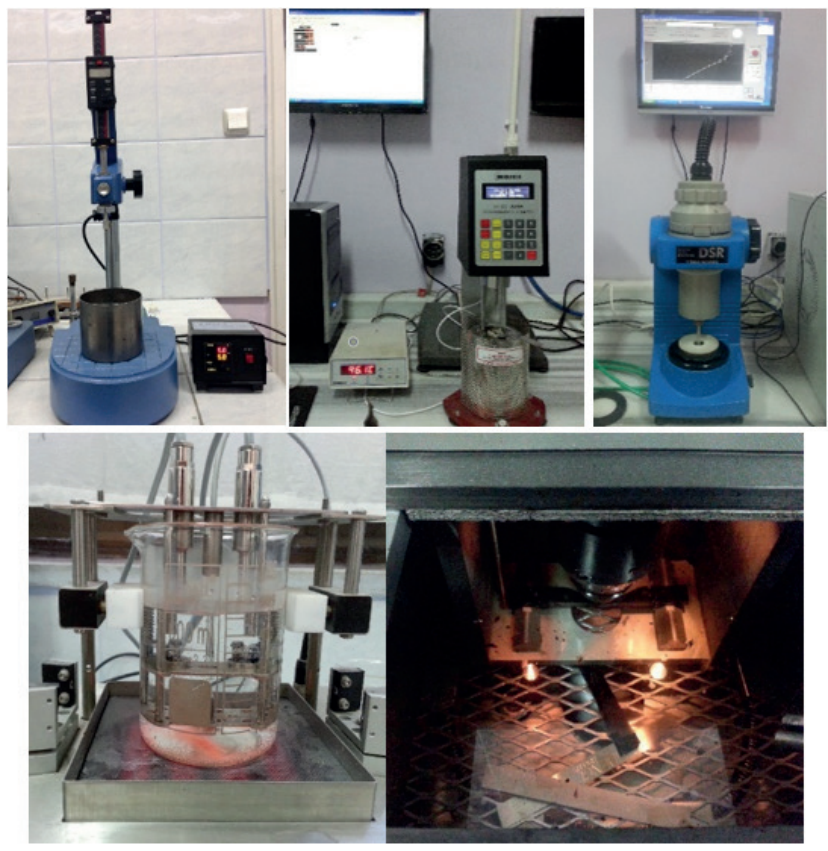

Fig. 2 Penetration, rotational viscosity, DSR, softening point, and BBR tests

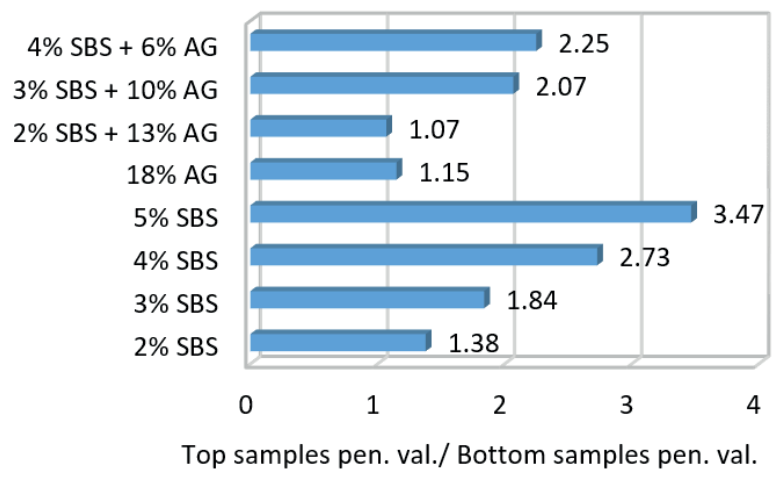

Fig. 3 Penetration value ratios of samples obtained from top of the tubes to bottom of the tubes

Table 2 Penetration, softening point and rotational viscosity test results

\begin{tabular}{|c|c|c|c|c|c|c|c|c|c|}
\hline & & \multicolumn{8}{|c|}{ Binder type } \\
\hline & & $\begin{array}{l}02 \\
0 \\
0 \\
\therefore \\
i\end{array}$ & 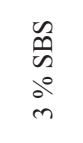 & $\begin{array}{l}\tilde{D} \\
\tilde{0} \\
\dot{0} \\
\dot{\nabla}\end{array}$ & 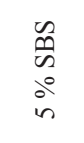 & 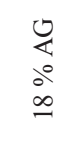 & 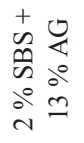 & 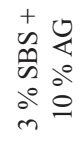 & 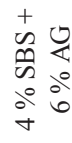 \\
\hline \multirow{2}{*}{$\begin{array}{l}\text { Penetration } \\
\quad\left(\mathrm{mm}^{-1}\right)\end{array}$} & Bottom & 61.1 & 46.9 & 35.1 & 25.3 & 21.2 & 26.4 & 23.1 & 23.7 \\
\hline & Top & 84.6 & 86.5 & 96.0 & 87.5 & 24.3 & 28.1 & 48.0 & 53.4 \\
\hline \multirow{2}{*}{$\begin{array}{l}\text { Softening point } \\
\left({ }^{\circ} \mathrm{C}\right)\end{array}$} & Bottom & 50.90 & 54.25 & 56.10 & 60.25 & 60.75 & 61.80 & 61.00 & 61.50 \\
\hline & Top & 68.05 & 77.20 & 81.05 & 85.35 & 64.05 & 69.50 & 81.75 & 79.05 \\
\hline \multirow{2}{*}{$\begin{array}{c}\text { Viscosity } \\
\left(\mathrm{cP}, @ 135^{\circ} \mathrm{C}\right)\end{array}$} & Bottom & 550 & 750 & 962.5 & 1238 & 1350 & 1275 & 1313 & 1263 \\
\hline & Top & 1050 & 2063 & 2825 & 4263 & 1363 & 2463 & 2638 & 3350 \\
\hline \multirow{2}{*}{$\begin{array}{c}\text { Viscosity } \\
\left(\mathrm{cP}, @ 165^{\circ} \mathrm{C}\right)\end{array}$} & Bottom & 175 & 212.5 & 262.5 & 300 & 325 & 300 & 300 & 312.5 \\
\hline & Top & 362.5 & 787.5 & 1050 & 1588 & 312.5 & 715.5 & 800 & 1350 \\
\hline
\end{tabular}


rates of modified binders, which only included SBS and was acquired from the top of the tubes, were between 85-96 $\mathrm{mm}^{-1}$. Additionally, in SBS modified binders, the samples acquired from the top of the tubes and included $3 \%, 4 \%$ and $5 \%$ SBS had higher penetration rates compared to $2 \%$ SBS modified bitumen. After the storage stability test, it was determined that, in $2 \%, 3 \%, 4 \%$ and $5 \%$ SBS modified bitumen, sample penetration rates obtained from the top of the tubes were 1.38, 1.84, 2.73 and 3.47 times higher than those of the samples acquired from the bottom of the tubes, respectively. This indicated that as SBS content increases, the disintegration between bitumen and polymer increases, as is reflected in storage stability.

Based on the penetration test results, it was determined that $18 \%$ AG modified bitumen was the most stable binder among modified binders in terms of storage stability. In $18 \%$ AG modified bitumen, it was determined that the samples acquired from the top of the tube had higher penetration rates than those acquired from the bottom, and the penetration rate of the top section was $15 \%$ higher compared to the bottom section. Modified binders with SBS and AG content, and $5 \%$ SBS content were compared to the binders, which had the same performance level $(2 \%$ $\mathrm{SBS}+13 \% \mathrm{AG}, 3 \% \mathrm{SBS}+10 \% \mathrm{AG}$ and $4 \% \mathrm{SBS}+6 \%$ $\mathrm{AG})$, and it was determined that, as SBS content increased in modified binders with SBS and AG content, the differences increased between the penetration rates after the storage stability test; however, the differences were lower between the penetration rates of binders with SBS and AG content than those with the $5 \%$ SBS. In SBS and AG modified binders, the best penetration result was obtained from the binders with $2 \% \mathrm{SBS}+13 \% \mathrm{AG}$.

According to the data obtained as a result of the statistical analyses for the penetration test, it was determined that there was not a significant relationship at the upper section of the tube with SBS use $(p>0.05)$ and AG addition created a significant relationship $(\mathrm{p}<0.5)$.

\subsection{Softening point test results}

Softening point tests results for the samples acquired from modified binders which were subjected to storage stability test are presented in Table 2. As seen in Table 2, softening point values of the samples obtained from the top of the tubes after the storage stability tests were higher than those of the samples acquired from the bottom of the tube. Only for the samples taken from the bottom of the tube after the storage stability tests, which were conducted on binders solely modified with SBS, it was determined that softening point increased as the SBS content increased. Since SBS density is lower than bitumen, polymer phase is collected on the top part of the tubes after the storage stability test [36]. Thus, the softening point rates were higher in the top section of the tubes.

The ratio of the softening point results of the top samples to bottom samples are seen in Fig. 4 . In $2 \%, 3 \%, 4 \%$ and $5 \%$ SBS modified bitumen, the softening points of samples acquired from the top of the tubes after the storage stability test were 1.34, 1.42, 1.42, 1.44 and 1.42 times higher than those of the samples acquired from the bottom of the tubes, respectively. Thus, as the SBS content increased, storage stability of bitumen decreased.

Similar to the penetration tests, in softening point tests, it was determined that $18 \%$ AG modified binder was the most stable modified bitumen for storage. Similar to other modified binders, it was determined that in $18 \%$ AG modified bitumen, the sample acquired from the top of the tube exhibited a higher softening point rate after storage stability test than that of the sample acquired from the bottom of the tube. In SBS and AG modified binders, it was determined that among the samples acquired from the top of the tube after the storage stability test, $3 \% \mathrm{SBS}+10 \% \mathrm{AG}$ modified binder exhibited the highest softening point rate.

In the comparison of $\mathrm{SBS}$ and $\mathrm{AG}$ modified binders (2\% SBS $+13 \%$ AG, $3 \%$ SBS $+10 \%$ AG and $4 \%$ SBS $+6 \% \mathrm{AG})$, it was determined that in these binders, as the SBS content increased, the difference increased as well between the softening point rates after the storage stability test; however, all softening point rate differences between SBS and AG modified binders were lower than those of the $5 \%$ SBS modification. In the comparison between $5 \%$ SBS modified binders, the softening point rates of the bitumen modified with $2 \% \mathrm{SBS}+13 \%$ AG, $3 \% \mathrm{SBS}+10 \%$ $\mathrm{AG}$ and $4 \% \mathrm{SBS}+6 \%$ AG were respectively $0.79,0.94$ and 0.91 times lower than that of $5 \%$ SBS modified bitumen after storage stability tests.

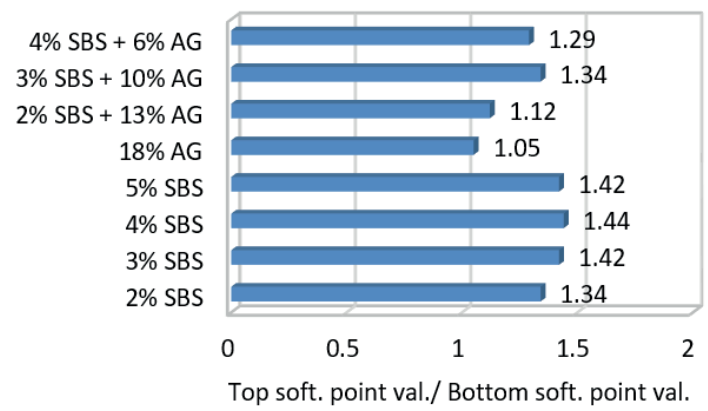

Fig. 4 The ratios of the softening point values obtained from the top part to the values obtained from the bottom part 
In the linear regression analysis conducted with the obtained results, it was determined that there was a significant relationship.

\subsection{Rotational viscometer test results}

Results of rotational viscometer tests conducted at $135{ }^{\circ} \mathrm{C}$ and $165^{\circ} \mathrm{C}$ on 8 different modified bitumen samples after the storage stability tests are presented in Table 2. The ratio of the top samples to the bottom samples concerning the rotational viscosity test results at 135 and $165{ }^{\circ} \mathrm{C}$ are seen in Fig. 5.

As seen in Fig. 5, in only SBS modified binders, it was determined that, as SBS content increased, viscosity values of the samples obtained from both the top and the bottom of the tubes increased. However, in the analysis of the samples acquired from the top of the tubes, it was determined that, as SBS content increased from $2 \%$ to $3 \%$, the viscosity rate increased by $117 \%$; as SBS content increased from $2 \%$ to $4 \%$ and $5 \%$, viscosity rates increased by $189 \%$ and $338 \%$, respectively. In the analysis of samples acquired from the bottom of the tubes, it was determined that as additive content increased from $2 \%$ to $3 \%, 4 \%$ and $5 \%$, viscosity rates increased by $21 \%, 50 \%$ and $71 \%$, respectively. This was due to the fact that polymer content was concentrated on the top section of the tube during the storage stability tests that were conducted on SBS modified bitumen.

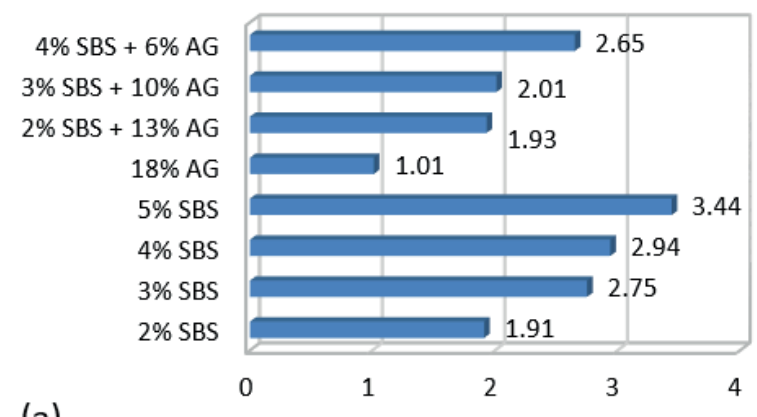

(a)

Top viscosity val./ Bottom viscosity val.

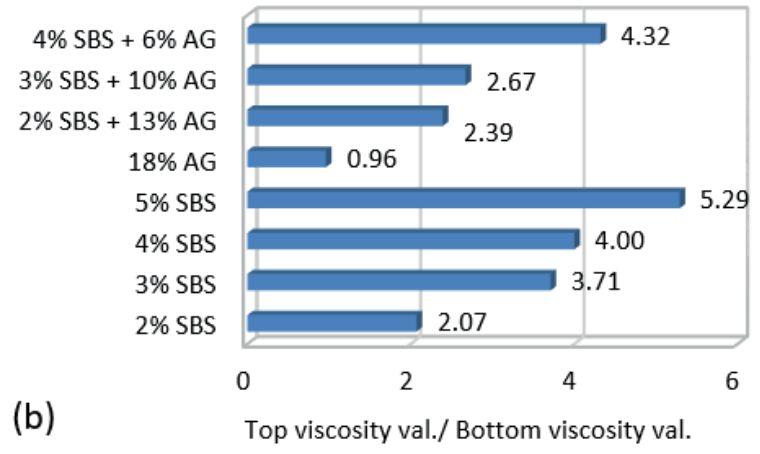

Fig. 5 The ratios of the viscosity values obtained from the top part to the values obtained from the bottom part a) $135^{\circ} \mathrm{C}$ b) $165^{\circ} \mathrm{C}$
In the analysis of viscosity rates of modified binders that exhibited the same performance levels after the storage stability test, it was determined that the samples acquired from the top of the tubes had higher viscosity rates compared to those of the samples acquired from the bottom of the tubes. It was determined that $5 \%$ SBS modified binder exhibited the highest viscosity rate, while $18 \%$ AG modified binder exhibited the lowest viscosity rate. Additionally, it was determined that the differences between the viscosity rates of samples acquired from the top and the bottom of the tubes were higher compared to the findings at $135^{\circ} \mathrm{C}$. This indicated that the disintegration between the samples acquired from the top and from the bottom was clearer following the storage stability tests conducted at high temperatures.

In the analysis of viscosity rates of binders with the same viscosity performances obtained after the storage stability tests, it was determined that $18 \%$ AG modified bitumen exhibited the best result and $5 \%$ SBS modified bitumen exhibited the worst result concerning the storage. It was determined that as SBS content increased in modified bitumen, the negation in terms of storage increased as well and storage stability decreased. This indicated that the use of $A G+v S B S$ would contribute to the storage of modified bitumen.

According to the statistical analysis conducted for the viscosity tests, it was determined that there were significant relationship at both $135^{\circ} \mathrm{C}$ and $165^{\circ} \mathrm{C}$.

\subsection{Bending beam rheometer test results}

BBR tests were designed to be conducted at $-10^{\circ} \mathrm{C}$ on samples obtained in storage stability test. Samples acquired in SBS modified binder storage stability tests demonstrated a polymeric structure, although in the BBR tests conducted at $-10^{\circ} \mathrm{C}$ and $-20^{\circ} \mathrm{C}$ on these samples, an excessive deflection occurred, and thus, no result was obtained. The standard BBR test was conducted on the samples following a storage for 24 hours at test temperature in order to obtain results. Although they were kept at $-20^{\circ} \mathrm{C}$ for 24 hours, in the samples acquired from the top of the tubes after storage stability test, the SBS modified bitumen did not produce results. This indicated that binders produced with solely SBS exhibited the worst results. Stiffness rates determined in the bending beam rheometer test, which was conducted on modified bitumen samples at $-20{ }^{\circ} \mathrm{C}$, are presented in Fig. 6 .

As seen in Fig. 6, in samples conditioned for both 1 hour and 24 hours, it was determined that as the SBS content increased in the samples obtained from the bottom of the tubes after the storage stability test, their stiffness rates 
increased as well. In the analysis of samples acquired from the bottom of the tubes, it was determined that AG addition to the SBS modified binders increased the stiffness rates. In the analysis of 24-hour conditioned samples, it was determined that samples acquired from the bottom of the tubes exhibited higher stiffness rates compared to those of the samples acquired from the top of the tubes. When all binders were considered, it was determined that $18 \%$ AG-modified binders exhibited the highest stiffness rates in mixtures conditioned for both 1 hour and 24 hours.

In only SBS $(2 \%, 3 \%, 4 \%$ and $5 \%$ SBS modified bitumen) modified binders, in samples acquired from the bottom of the tubes after the storage stability test, increasing the conditioning from 1 hour to 24 hours led to 1.89 , 1.80, 1.93 and 2.04-fold increases in stiffness, respectively. In AG + SBS modified binders, in samples acquired from the bottom of the tubes, increasing the conditioning from 1 hour to 24 hours caused the stiffness to increase 1.22 times in $2 \% \mathrm{SBS}+13 \% \mathrm{AG}$ and $3 \% \mathrm{SBS}+10 \%$ AG modified binders, and 1.13 times in $4 \% \mathrm{SBS}+6 \% \mathrm{AG}$ modified binders. This increase was 1.37 times for $18 \%$ AG modified binder. After the storage stability tests, in $18 \%$ AG, $2 \%$ SBS + $13 \%$ AG, $3 \%$ SBS + $10 \%$ AG and $4 \% \mathrm{SBS}+6 \%$ AG modified binders, in the samples acquired from the top of the tubes, increasing the conditioning from 1 hour to 24 hours caused the stiffness to increase $1.20,1.31,1.47$ and 1.30 -fold, respectively.

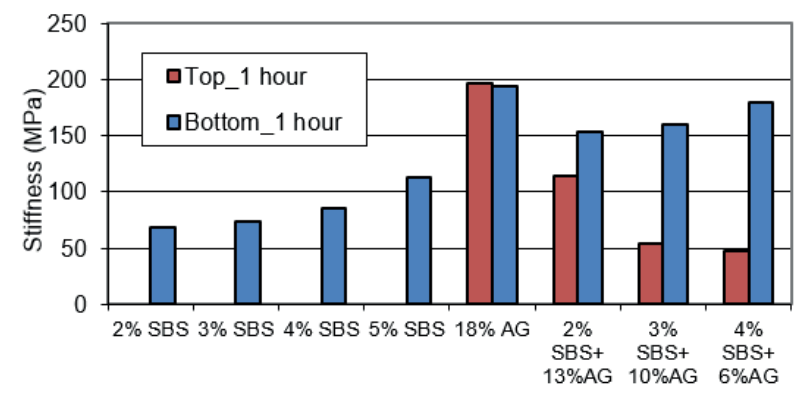

(a)

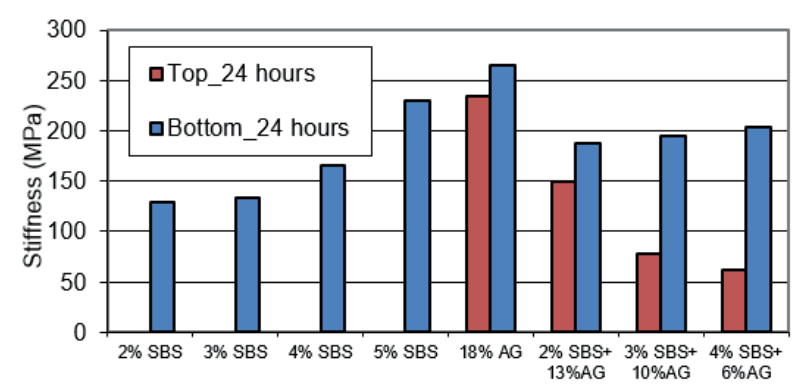

(b)

Fig. 6 Stiffness of 1 hour (a) and 24 hours (b) conditioned samples obtained in the storage stability test
In only SBS modified binders, the fact that it was not possible to determine the stiffness of samples acquired from the top of the tubes after the storage stability tests indicated that SBS modified binders were the worst for storage stability. In 1 hour-conditioned $18 \%$ AG modified binders, the difference between the stiffness of samples obtained from the top and the bottom of the tubes was $1.3 \%$, while the differences were $25.56 \%, 56.62 \%$ and $73.32 \%$ for $2 \% \mathrm{SBS}+13 \%$ AG, $3 \% \mathrm{SBS}+10 \% \mathrm{AG}$, and $4 \% \mathrm{SBS}$ $+6 \%$ AG modified binders respectively. In 24-hour conditioned binder samples, the difference between the stiffness of $18 \%$ AG, $2 \% \mathrm{SBS}+13 \%$ AG, $3 \% \mathrm{SBS}+10 \%$ $\mathrm{AG}$ and $4 \% \mathrm{SBS}+6 \% \mathrm{AG}$ modified binder samples obtained from the top and the bottom of the tubes were $11.48 \%, 20.02 \%, 53.74 \%$ and $69.35 \%$, respectively. In SBS and AG-modified binders, for the samples acquired from the top of the tubes, as the SBS content increased, the stiffness rates decreased, while in samples acquired from the bottom of the tubes, as the SBS content increased, the stiffness rates increased as well. This indicated that as the SBS content increased, modified binders demonstrated a negative behavior in terms of storage. The m-values obtained from the bending beam rheometer tests, which were conducted on modified binder samples acquired after the storage stability tests, are presented in Fig. 7.

In the analysis of $m$-values that demonstrate the changes in deformation during the application of the load on binders at $-20{ }^{\circ} \mathrm{C}$, it was determined that $5 \%$ SBS modified bitumen samples acquired from the bottom of the tubes after the storage stability tests exhibited the highest $m$-value. This indicated that independent of the intensity of the disintegration, polymers were still present at the bottom of the tubes, and thus their m-values were higher. Furthermore, in solely SBS-modified binders, the fact that samples acquired from the top of the tubes after the storage stability test did not yield any result was due to excessive deflection induced by the load applied. In AG-modified

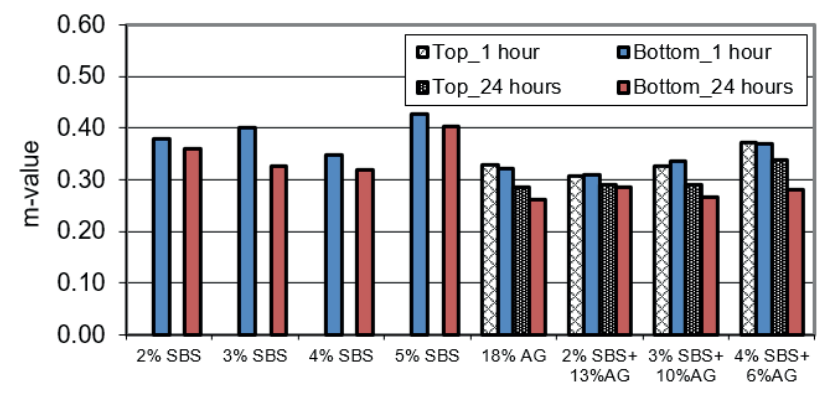

Fig. 7 m-values for 1 hour and 24 hours conditioned samples obtained with the storage stability test 
bitumen, the fact that $\mathrm{m}$-value was low indicated that there may be low temperature cracking problems in AG-modified bitumen. The ratio of the sample stiffness rate to $\mathrm{m}$-value ( $\mathrm{S} / \mathrm{m}$-value) are presented in Fig. 8.

The ratio of sample stiffness to $\mathrm{m}$-values ( $\mathrm{S} / \mathrm{m}$-value) is a parameter used to characterize the behavior of binders at low temperatures [37]. A low rate indicates that the binder would behave better under low temperatures. Analysis of the data presented in Fig. 8 demonstrated that the bitumen samples with the best low temperature performances were the SBS-modified binders and the worst low temperature performances were obtained in only AG-modified binders. In the analysis of these findings based on the effects of the temperatures and disintegration, it was determined that in binders with the same performance, AG-modified binders exhibited more proper results.

In the assessment of all BBR tests, it was observed that SBS-modified binders had a negative effect on storage; however, the SBS-modified binders demonstrated more elastic behavior at low temperatures despite the disintegration. In the evaluation of binders with the same performance level, it was determined that the use of SBS and AG together produced better results compared to SBS modification based on storage, and it was more flexible compared to solely AG-modified binders.

\subsection{Dynamic mechanical test results}

In the study, for the binder samples that were tested for storage stability, dynamic shear rheometer tests were also conducted at 4 different temperatures $\left(40{ }^{\circ} \mathrm{C}, 50^{\circ} \mathrm{C}, 60^{\circ} \mathrm{C}\right.$, $70{ }^{\circ} \mathrm{C}$ ) and 10 different frequencies ranging between 0.01 and $4 \mathrm{~Hz}$. The test results were plotted as master curves. The complex shear modulus $\left(\mathrm{G}^{*}\right)$ findings for the SBSmodified binder samples obtained from the bottom of the tubes after the storage stability test are presented in Fig. 9(a) and $\mathrm{G}^{*}$ results of samples acquired from the top of the tubes are presented in Fig. 9 (b).

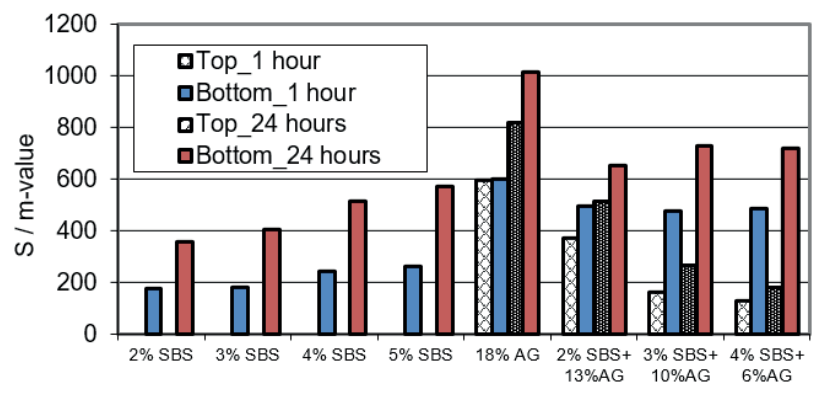

Fig. $8 \mathrm{~S} / \mathrm{m}$-values for 1 hour and 24 hours conditioned samples obtained with the storage stability test

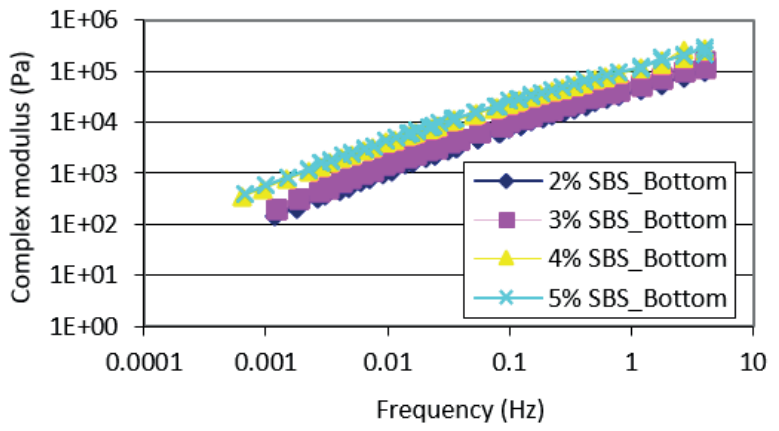

(a)

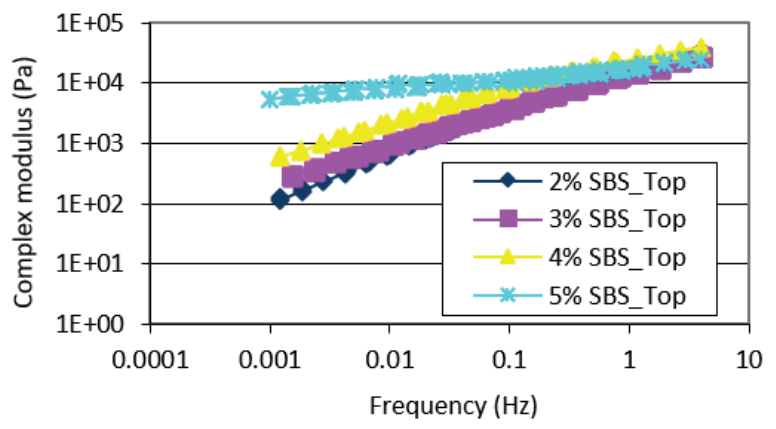

(b)

Fig. 9 Complex modulus master curves for SBS modified binders

As seen in Fig. 9(a), as SBS content and frequency increased, $\mathrm{G}^{*}$ values increased as well. Among all SBSmodified binder samples acquired from the bottom of the tubes after the storage stability test and in all frequencies, it was observed that $2 \%$ SBS modified binder exhibited the lowest $\mathrm{G}^{*}$ value, while $5 \%$ SBS modified binder exhibited the highest $\mathrm{G}^{*}$ value. It was determined that the changes in sample $G^{*}$ values acquired from the bottom of the tubes with the same frequency were similar in all binders.

As seen in Fig. 9(b), as SBS content increased, the changes in $\mathrm{G}^{*}$ values of SBS-modified bitumen samples acquired from the top of the tubes decreased with frequency. It is considered that this was due to the fact that SBS's density was lower compared to the bitumen, and thus SBS accumulated on the top of the tube during storage stability tests. The SBS accumulation on top of the tubes caused the samples to reflect a polymeric structure, and thus as SBS content increased, the effect of the changes in frequency on the samples decreased.

$\mathrm{G}^{*}$ values for the binder samples acquired from the top and the bottom of the tubes with the same performances are presented in Fig. 10.

As seen in Fig. 10 (a), it was determined that $G^{*}$ values of the samples with the same performance level that are acquired from the bottom of the tubes after the storage stability tests were similar and the changes observed in these values with the frequency change were also similar. 


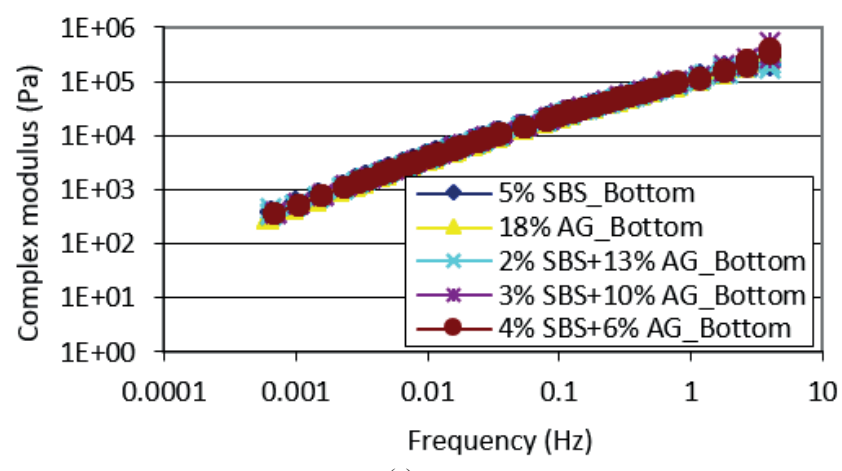

(a)

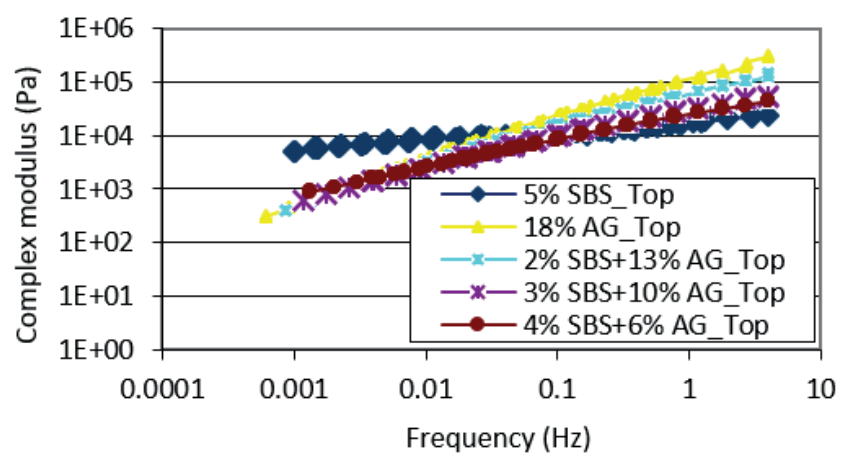

(b)

Fig. 10 Complex modulus master curves for modified binders with the same performance grade

As seen in Fig. 10(b), the binder samples with the same performance level that are acquired from the top of the tubes after the storage stability tests had similar values in low frequencies, with the exception that the $5 \%$ SBS modified binder and the $18 \%$ AG modified binder had the highest rate in high frequencies. It was detected that $5 \%$ SBS modified binder samples had the lowest rate at high frequencies. Complex Modulus values of the samples obtained from the top and the bottom of the tubes are summarized in Tables 3 and 4 .

As seen in Table 3, as SBS content increased in both the top and the bottom in modified bitumen, $\mathrm{G}^{*}$ values were higher in $0.001,0.01$ and $0.1 \mathrm{~Hz}$ frequencies. It was determined that these changes were not regular at 1 and $4 \mathrm{~Hz}$ frequencies. It was detected that as the SBS content increased, the difference increased between the DSR test findings for samples acquired from the top and the bottom of the tubes at $4 \mathrm{~Hz}$ frequency; in $5 \%$ SBS including binders, this difference was 13.2-fold. In the analysis of the changes in DSR test results concerning frequency, it was determined that samples acquired from the bottom of the tubes were affected more by the changes in frequency. As SBS content increased, the effect of the frequency decreased. Especially in $5 \%$ SBS modification, there was a 7.6-time difference between the $G^{*}$ values of the samples acquired from the bottom of the tubes at $0.001 \mathrm{~Hz}$ and $0.01 \mathrm{~Hz}$, while the difference was 506.7 -fold when the frequency was increased from $0.001 \mathrm{~Hz}$ to $4 \mathrm{~Hz}$. In $5 \%$ SBS modified bitumen samples obtained from the top of the tubes, the $\mathrm{G}^{*}$ value increased 1.6 times when the frequency was increased from $0.001 \mathrm{~Hz}$ to $0.01 \mathrm{~Hz}$, while the $\mathrm{G}^{*}$ value increased only 4.3 times when the frequency was increased from 0.001 to $4 \mathrm{~Hz}$.

In the analysis of $\mathrm{G}^{*}$ values for binders with the same performance level (Table 4), it was determined that among the samples acquired from the top and the bottom of the tubes, $18 \%$ AG modified binder samples exhibited the lowest difference between the DSR test results, while $5 \%$ SBS modified binder samples exhibited the highest difference. At $4 \mathrm{~Hz}$ frequency, in the DSR tests results for the $18 \%$ AG modified binder samples acquired from the top and the bottom of the tubes, the difference between

Table 3 DSR test results for SBS modified binders

\begin{tabular}{|c|c|c|c|c|c|c|}
\hline \multirow{2}{*}{\multicolumn{2}{|c|}{$\begin{array}{c}\text { Specimen type } \\
0.001\end{array}$}} & \multicolumn{5}{|c|}{ Frequency (Hz) } \\
\hline & & \multirow{2}{*}{$\frac{0.01}{121}$} & \multirow{2}{*}{$\frac{0.1}{1062}$} & \multirow{2}{*}{$\frac{1}{7537}$} & \multicolumn{2}{|l|}{4} \\
\hline \multirow{2}{*}{$\begin{array}{l}\circ \mathscr{n} \\
\text { तथ }\end{array}$} & Bottom & & & & 38128 & 107900 \\
\hline & Top & 102 & 679 & 3873 & 15109 & 34020 \\
\hline \multirow{2}{*}{ 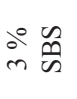 } & Bottom & 178 & 1521 & 10180 & 50304 & 129500 \\
\hline & Top & 229 & 928 & 4047 & 14168 & 27300 \\
\hline \multirow{2}{*}{ 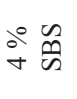 } & Bottom & 525 & 3965 & 22860 & 103226 & 287000 \\
\hline & Top & 541 & 2210 & 8792 & 23707 & 38600 \\
\hline \multirow{2}{*}{$\begin{array}{l}\circ \stackrel{n}{\circ} \\
\text { in }\end{array}$} & Bottom & 579 & 4400 & 25440 & 108075 & 293400 \\
\hline & Top & 5161 & 8305 & 10935 & 17500 & 22239 \\
\hline
\end{tabular}

Table 4 DSR test results for modified binders with the same performance grade

\begin{tabular}{|c|c|c|c|c|c|c|}
\hline \multirow{2}{*}{\multicolumn{2}{|c|}{$\begin{array}{c}\text { Specimen type } \\
0.001\end{array}$}} & \multicolumn{5}{|c|}{ Frequency $(\mathrm{Hz})$} \\
\hline & & \multirow{2}{*}{$\begin{array}{l}0.01 \\
579\end{array}$} & \multirow{2}{*}{$\frac{0.1}{4400}$} & \multirow{2}{*}{$\frac{1}{25440}$} & \multicolumn{2}{|l|}{4} \\
\hline \multirow{2}{*}{$\begin{array}{l}\circ 0 \\
\text { in } \tilde{n}\end{array}$} & Bottom & & & & 108075 & 293400 \\
\hline & Top & 5161 & 8305 & 10935 & 17500 & 22239 \\
\hline \multirow{2}{*}{$\stackrel{\circ}{\infty}$} & Bottom & 469 & 3653 & 22420 & 99850 & 372700 \\
\hline & Top & 499 & 3874 & 24010 & 110657 & 287700 \\
\hline 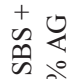 & Bottom & 508 & 3885 & 22840 & 110346 & 222100 \\
\hline$\stackrel{\circ}{\sim}=$ & Top & 454 & 3191 & 15950 & 58888 & 127200 \\
\hline $\begin{array}{l}+ \\
\text { ñ } \\
n \\
\sim\end{array}$ & Bottom & 523 & 3966 & 25000 & 114318 & 334800 \\
\hline$i^{\circ} \circ$ & Top & 569 & 2504 & 10280 & 29766 & 52530 \\
\hline $\begin{array}{ll}+ & \\
\tilde{n} & 0 \\
\tilde{n} & 0 \\
0\end{array}$ & Bottom & 497 & 3769 & 23260 & 101629 & 346400 \\
\hline oे & Top & 804 & 2324 & 8889 & 24619 & 43920 \\
\hline
\end{tabular}


$\mathrm{G}^{*}$ values was only 1.3 -fold, while in $5 \%$ SBS modified binder samples, the increase was 13.2-fold. For the binders with the same performance level, as SBS content decreased, the difference decreased between $G^{*}$ values of the samples acquired from the top and the bottom of tubes after the storage stability test. Thus, it was determined that, for storage stability, AG use would produce more stable results compared to SBS modification.

\section{Conclusions}

In the present study, 4 SBS modified bitumen, $3 \mathrm{SBS}+\mathrm{AG}$ modified bitumen and 1 AG modified bitumen were investigated based on storage stability properties. Based on the results of penetration, softening point, rotational viscometer, bending beam rheometer and dynamic shear rheometer tests conducted on samples obtained with the storage stability tests, the following conclusions were reached.

- The penetration tests conducted on the binders demonstrated that the penetration rates for the samples that were acquired from the top of the tubes after the storage stability test were higher compared to those of the samples acquired from the bottom of the tubes. It was also determined that as SBS content increased at the bottom of the tubes, penetration rates decreased, thus, stability increased. According to the results of penetration tests, it was determined that the most stable modified binder was $18 \%$ AG modified bitumen based on storage stability. The most stable binder among SBS and AG modified binders was the $2 \% \mathrm{SBS}+13 \% \mathrm{AG}$ modified bitumen based on storage stability, and the most instable binder was $5 \%$ SBS modified bitumen.

- Based on the softening point test results, the softening point rates of all modified bitumen samples acquired from the top of the tubes were higher compared to those of the samples acquired from the bottom of the tubes. It was determined that, in the solely-SBS-modified bitumen following the storage stability test, SBS accumulated on the top of the tubes due to its density, thus as SBS content increased, softening point increased in the top of the tubes. In comparison of the binders with the same performance level (2\% SBS + $13 \%$ AG, $3 \%$ $\mathrm{SBS}+10 \% \mathrm{AG}, 4 \% \mathrm{SBS}+6 \% \mathrm{AG}, 5 \% \mathrm{SBS}$ and $18 \% \mathrm{AG})$, for SBS and AG modified binders, it was determined that as SBS content increased, the difference between the softening point values increased after the storage stability test; $18 \%$ AG modified bitumen exhibited the best storage stability result and $5 \%$ SBS modified bitumen exhibited the worst result.
- In the analysis of viscosity test results for bitumen after storage stability tests, it was determined that samples obtained from the top of the tubes exhibited higher rates compared to the samples acquired from the bottom of the tubes. In the comparison of the samples obtained from the top of the tubes, it was determined that $5 \%$ SBS modified binders had the highest viscosity rates and $18 \%$ AG modified binders had the lowest viscosity rates. It was determined that as SBS content increased in the modified bitumen, its negative effect on storage stability increased and storage stability decreased. This indicated that the use of AG instead of SBS in bitumen modification yielded better results concerning the storage stability.

- The bending beam rheometer test results demonstrated that SBS modification exhibited negative effects on storage stability; however, SBS modified binders demonstrated elastic behavior at low temperatures despite the experienced disintegration. The analysis of binders with the same performance level demonstrated that the use of both SBS and AG in modification produced better storage stability results compared to only SBS modification and more flexible binders were obtained compared to binders modified only with AG.

- DSR test results demonstrated that as SBS content and frequency increased, $\mathrm{G}^{*}$ values increased as well; moreover, when samples acquired from the bottom of the tubes were analyzed, $2 \%$ SBS modified binder exhibited the lowest values at all frequencies, while $5 \%$ SBS modified bitumen exhibited the highest values. It was detected that difference between the $\mathrm{G}^{*}$ values of all binder samples acquired from the bottom of the tubes after the storage stability test were similar concerning the frequency. As SBS content increased, the amount of difference between the $G^{*}$ values of the samples acquired from the top of the tubes after the storage stability tests decreased with frequency. It was suggested that this was due to the fact that SBS density is lower compared to the bitumen, and thus SBS accumulated on the top of the tube during the storage stability tests. As a result of DSR tests, it was determined that the highest difference between complex shear modulus of samples collected from the top and the bottom of the tubes was observed in $5 \%$ SBS modified binders. This indicated that the use of both Gilsonite and SBS in modified binder storage would be more advisable based on the complex shear modulus. 
Based on the results of all conducted tests, it can be concluded that more flexible binders could be obtained with SBS + AG modification to improve storage stability.

\section{References}

[1] Jones, R. "Modifiers for Asphalt Concrete", Air Force Engineering and Service Center, Novato, CA, USA, Rep. ESL-TR-88-29, 1990.

[2] Giavirini, C., Mastrofini, D., Scarsella, M., Barré, L., Espinat, D. "Macrostructure and Rheological Properties of Chemically Modified Residues and Bitumens", Energy \& Fuels, 14, pp. 495502,2000

https://doi.org/10.1021/ef9902045

[3] Salas, M. A., Perez-Acebo, H., Calderon, V., Gonzalo-Orden, H. "Bitumen modified with recycled polyurethane foam for employment in hot mix asphalt", Ingeniería e Investigación, 38(1), pp. 60-66, 2018.

https://doi.org/10.15446/ing.investig.v38n1.65631

[4] Siddig, E. A. A., Feng, C. P., Ming, L. Y. "Effects of ethylene vinyl acetate and nanoclay additions on high-temperature performance of asphalt binders", Construction and Building Materials, 169, pp. 276-282, 2018.

https://doi.org/10.1016/j.conbuildmat.2018.03.012

[5] Smagulova, N., Kairbekov, Z., Aubakirov, E., Yemoldina, E. "Production of Bitumens from Coal Sources Modified by Elementary Sulfur", Advanced Materials Research, 535-537, pp. 1815-1818, 2012.

https://doi.org/10.4028/www.scientific.net/AMR.535-537.1815

[6] Topal, A. "Evaluation of the properties and microstructure of plastomeric polymer modified bitumens", Fuel Processing Technology, 91(1), pp. 45-51, 2010.

https://doi.org/10.1016/j.fuproc.2009.08.007

[7] Vila-Cortavitarte, M., Lastra-Gonzalez, P., Calzada-Pérez, M. A., Indacoechea-Vega, I. "Analysis of the influence of using recycled polystyrene as a substitute for bitumen in the behavior of asphalt concrete mixtures", Journal of Cleaner Production, 170, pp. 1279$1287,2018$.

https://doi.org/10.1016/j.jclepro.2017.09.232

[8] Yousefi, A. A. "Polyethylene dispersions in bitumen: The effects of the polymer structural parameters", Journal of Applied Polymer Science, 90(12), pp. 3183-3190, 2003.

https://doi.org/10.1002/app.12942

[9] Şengoz, B., Topal, A. "Use of asphalt roofing shingle waste in HMA", Construction and Building Materials, 19(5), pp. 337-346, 2005.

https://doi.org/10.1016/j.conbuildmat.2004.08.005

[10] Isacsson, U., Lu, X. "Testing and appraisal of polymer modified road bitumens - state of the art", Materials and Structures, 28(3), pp. 139-159, 1995. https://doi.org/10.1007/BF02473221

[11] Zorn, S., Mehta, Y., Dahm, K., Batten, E., Nolan, A., Dusseau, R. "Rheological Properties of the Polymer Modified Bitumen with Emphasis on SBS Polymer and Its Microstructure", Road Materials and New Innovations in Pavement Engineering, 2012. https://doi.org/10.1061/47634(413)6

\section{Acknowledgement}

This study was conducted as a part of MF.14.22 numbered Frrat University Scientific Research Projects program (FÜBAP). Authors thank FÜBAP for its support.

[12] Yilmaz, M., Çeloğlu, M. E. "Effects of SBS and different natural asphalts on the properties of bituminous binders and mixtures", Construction and Building Materials, 44, pp. 533-540, 2013. https://doi.org/10.1016/j.conbuildmat.2013.03.036

[13] Gorkem, C., Sengoz, B. "Predicting stripping and moisture induced damage of asphalt concrete prepared with polymer modified bitumen and hydrated lime", Construction and Building Materials, 23(6), pp. 2227-2236, 2009.

https://doi.org/10.1016/j.conbuildmat.2008.12.001

[14] Topal, A., Yilmaz, M., Kok, B. V., Kuloglu, N., Sengoz, B. "Evaluation of rheological and image properties of styrene-butadiene-styrene and ethylene-vinyl acetate polymer modified bitumens", Journal of Applied Polymer Science, 122(5), pp. 3122-3132, 2011.

https://doi.org/10.1002/app.34282

[15] Sonmez, I., Deniz, M. T., Tayfur, S., Ozen, H., Yildirim, S. A., Eren, B. K. "Effects of modifiers on the hot mix asphalt performance", In: 6th Transportation Congress, Istanbul, Turkey, 2005, pp. 334-348.

[16] Liu, J., Li, P. "Experimental Study on Gilsonite-Modified Asphalt", In: Proceeding of the 2008 Airfield and Highway Pavement Specialty Conference, Washington, DC, USA, 2008, pp. 222-228. https://doi.org/10.1061/41005(329)20

[17] Ameri, M., Mansourian, A., Ashani, S. S., Yadollahi, G. "Technical study on the Iranian Gilsonite as an additive for modification of asphalt binders used in pavement construction", Construction and Building Materials, 25(3), pp. 1379-1387, 2011. https://doi.org/10.1016/j.conbuildmat.2010.09.005

[18] Hamidi, H. "Stiffness modulus and permanent deformation characteristics of asphalt mix containing Gilsonite", PhD Thesis, Bandung Institute of Technology, 1998.

[19] Kök, B. V., Yilmaz, M., Guler, M. "Evaluation of high temperature performance of SBS + gilsonite modified binder", Fuel, 90(10), pp. 3093-3099, 2011 https://doi.org/10.1016/j.fuel.2011.05.021

[20] Masson, J.-F., Collins, P., Robertson, G., Woods, J. R., Margeson, J. "Thermodynamics, Phase Diagrams, and Stability of BitumenPolymer Blends", Energy \& Fuels, 17(3), pp. 714-724, 2003. https://doi.org/10.1021/ef0202687

[21] Chen, J. S., Liao, M. C., Shiah, M. S. "Asphalt Modified by Styrene-Butadiene-Styrene Triblock Copolymer: Morphology and Model", Journal of Materials in Civil Engineering, 14(3), pp. 224-229, 2002 https://oi.org/10.1061/(ASCE)0899-1561(2002)14:3(224)

[22] Airey, G. D. "Styrene butadiene styrene polymer modification of road bitumens", Journal of Materials Science, 39(3), pp. 951-959, 2004.

https://doi.org/10.1023/B:JMSC.0000012927.00747.83 
[23] Zhu, J. "Storage Stability and Phase Separation Vehaviour of Polymer-Modified Bitumen: Characterization and Modelling", $\mathrm{PhD}$ thesis, KTH Royal Institute of Technology, 2016. [online] Available at: http://kth.diva-portal.org/smash/record.jsf?pid=diva2\%3A1044013\&dswid=-129 [Accessed: 07 July 2019]

[24] Wang, T., Yi, T., Yuzhen, Z. "The Compatibility of SBS-Modified Asphalt, Petroleum Science and Technology", 28(7), pp. 764-772, 2010. https://doi.org/10.1080/10916460902937026

[25] Wen, G., Zhang, Y., Zhang, Y., Sun, K., Fan, Y. "Rheological characterization of storage-stable SBS-modified asphalts", Polymer Testing, 21(3), pp. 295-302, 2002. https://doi.org/10.1016/S0142-9418(01)00086-1

[26] Galooyak, S. S., Dabir, B., Nazarbeygi, A. E., Moeini, A. "Rheological properties and storage stability of bitumen/SBS/ montmorillonite composites", Construction and Building Materials, 24(3), pp. 300-307, 2010.

https://doi.org/10.1016/j.conbuildmat.2009.08.032

[27] Kök, B. V., Yılmaz, M., Kuloğlu, N., Alataş, T. "Investigation of the Rheological Properties of SBS Modified Binder Produced by Different Methods", Journal of Engineering and Natural Sciences, 29, pp. 272-288, 2011. [online] Available at: http://eds.yildiz.edu. tr/ArticleContent/Journal/sigma/Volumes/2011/Issues/Regular-3/ YTUJENS-2011-29-3.168.pdf [Accessed: 12 May 2019]

[28] Yilmaz, M., Erdoğan Yamaç, Ö. "Evaluation of Gilsonite and Styrene-Butadiene-Styrene Composite Usage in Bitumen Modification on the Mechanical Properties of Hot Mix Asphalt", ASCE Journal of Materials in Civil Engineering, 29(9), 2017. https://doi.org/10.1061/(ASCE)MT.1943-5533.0001938

[29] CEN "DIN EN 13399 Bitumen and bituminous binders. Determination of storage stability of modified bitumen", Deutsches Institut für Normung, Berlin, Germany, 2010.
[30] DIN "EN 1426 Bitumen and bituminous binders. Determination of needle penetration", Deutsches Institut für Normung, Berlin, Germany,2015.

[31] DIN "EN 1427 Bitumen and bituminous binders. Determination of the softening point-ring and ball method", Deutsches Institut für Normung, Berlin, Germany, 2015.

[32] ASTM "D 4402 Standard test method for viscosity determination of asphalt at elevated temperatures using a rotational viscometer", American Society for Testing and Materials, West Conshohocken, PA, USA, 2006.

[33] AASHTO "TP1 Standard test method for determining the flexural creep stiffness of asphalt binder using the bending beam rheometer (BBR)", American Association of State Highway and Transportation Officals, Washington, DC, USA, 1998.

[34] McGennis, R. B., Shuler, S., Bahia, H. U. "Background of superpave asphalt binder test methods", U.S. Department of Transportation Federal Highway Administration, Washington, DC, USA, Rep. FHWA-SA-94-069, 1994.

[35] Airey, G. D., Hunter, A. E, Rahimzadeh, B. "The influence of geometry and sample preparation on dynamic shear rheometer testing", In: Performance of Bituminous and Hydraulic Materials in Pavements: Proceedings of the Fourth European Symposium, Bitmat4, Nottingham, UK, 2002, pp. 3-12.

[36] Yilmaz, M., Kök, B. V., Erdoğan Yamaç, Ö. "Determination of rheological properties of polymer and natural asphalts modifiers binders after storage stability test", SIGMA Journal of Engineering and Natural Sciences, 33, pp. 157-165, 2015.

[37] Edwards, Y., Tasdemir, Y., Isacsson, U. "Rheological effects of commercial waxes and polyphosphoric acid in bitumen 160/220-low temperature performance", Fuel, 85(7-8), pp. 989-997, 2006. https://doi.org/10.1016/j.fuel.2005.09.014 